\title{
Feto-maternal outcome in previous one cesarean section: a retrospective observational study at a district hospital of Jharkhand
}

\author{
Tanu Sharma*, Suchita Singh
}

Department of Obstetrics and Gynecology, PJMCH, Dumka, Jharkhand, India

\author{
Received: 27 July 2021 \\ Accepted: 31 August 2021 \\ *Correspondence: \\ Dr. Tanu Sharma, \\ E-mail: tanisha.anu@gmail.com
}

Copyright: () the author(s), publisher and licensee Medip Academy. This is an open-access article distributed under the terms of the Creative Commons Attribution Non-Commercial License, which permits unrestricted non-commercial use, distribution, and reproduction in any medium, provided the original work is properly cited.

\begin{abstract}
Background: Cesarean section is one of the most common surgery done in department of obstetrics and gynecology. It becomes more complicated in cases of high risk pregnancy like PIH, APH etc. Its rate is increasing day by day. Once a CS, always a CS, is questionable but being followed up at various set up due to various reasons. Today, one of the important indications of repeat CS is previous CS which increases the rate of CS in a particular set up and morbidities associated with multiple CS. According to ACOG guidelines, VBAC should be attempted to decrease the incidence of repeat CS and morbidity among them. This study was conducted to analyze the incidence of subsequent CS in previous one CS cases, demographic variables and feto-maternal outcome in previous CS patients.

Methods: This was a retrospective observational study on previous CS patients, carried out in District hospital, Dumka, Jharkhand. The rates, demography and feto-maternal outcome among previous one CS patients were studied during 1 year duration and data was obtained from labor room and medical record department.

Results: Out of 2947 deliveries, 63 patients had previous one cesarean section, the incidence being 2.13\%. 39.7\% deliver vaginally while $60.3 \%$ needed repeat cesarean section. Majority (95.2\%) were in 21-30yrs age group, $76.2 \%$ were unbooked and $25.4 \%$ were tribal population. Maximum $(79.4 \%$ ) were gravid 2 and $93.7 \%$ were term. $93.7 \%$ had birth space $>18$ months. Out of 38 repeat cesarean section, $78.9 \%$ underwent emergency cesarean section. The most common indication being scar tenderness $(39.5 \%)$ followed by CPD (15.8\%). Intraoperatively, severe adhesions found in $15.8 \%$ cases, bladder adherence in $18.4 \%$ cases and $2.6 \%$ had adherent placenta. PPH occurred in $4.8 \%$ cases and blood transfusion or injectable iron therapy required in $25.4 \%$ cases. $4.7 \%$ had wound infection, $7.9 \%$ had prolong hospital stay and $22.2 \%$ cases required prolong foley's catheterization. There was no maternal mortality. $95 \%$ babies born alive, $3.2 \%$ was stillbirth, $1.5 \%$ was IUD and the neonatal death rate was $3.2 \%$.

Conclusions: Previous cesarean section is one of the most important causes of CS in subsequent pregnancies, hence increase in the rates of CS and the morbidities associated with multiple CS among mothers. Thus the decision of CS in primigravida should be taken wisely and practice of CS on demand should be discouraged.
\end{abstract}

Keywords: VBAC, CS, TOLAC, Trial of labor, TTN, Maternal morbidity, Perinatal outcome

\section{INTRODUCTION}

Cesarean is the one of the most common surgery done in obstetrics department. ${ }^{1}$ In modern era its incidence has increased due to advancement in obstetric care, anesthetic techniques and intensive care machines. It was always a preferable option for an obstetrician to reduce maternal and fetal morbidity in cases of high risk pregnancy and in fetal distress. Its rate has increased dramatically in past $50 y$ rs in both eastern and western world. ${ }^{2}$ The reason for persistent increase may be small family norms, rising elderly primigravida with more risk in pregnancy, early detection of fetal distress with electronic fetal monitoring, reduction in instrumental delivery due to fear of high 
maternal and fetal morbidity and litigation by patient, more labor induction so more chances of failure, decrease in VBAC because of comparatively increase fetomaternal morbidity than cesarean in previous cesarean section patients, ART, and an important indication is on maternal request due to fear of pelvic floor injury and fetal injury during vaginal birth or due to fear of labor pains. ${ }^{3}$ CDMR decreases the rate of birth trauma, infection and HIE but it should not be motivated because of complications like placenta previa, adhesions, rupture uterus and risk of cesarean hysterectomy in next pregnancy. Once a cesarean, always a cesarean, quoted by Cragin in 1916 has been questioned by NIH in 1981 and enthusiastic attempt of VBAC were begun to increase after encouragement from ACOG $(1988,1994)$ but it has been questioned again because TOLAC has increase rate of uterine rupture and related feto-maternal morbidity and mortality so ACOG directed to attempt trials only in appropriately equipped institutions. ${ }^{3}$ Today economic, staffing and medico-legal factors shape the decision to offer TOLAC. Elective cesarean is a $2^{\text {nd }}$ choice. TOLAC should only be given in non- recurrent causes of cesarean section and if previous cesarean interval more than 18 months. It should be contraindicated in previous classical or inverted-T incision, previous history of uterine rupture, contracted pelvis and medical or obstetrical complications that precludes vaginal birth like placenta previa. ${ }^{3}$ A previous cesarean casts "a shadow over any future pregnancy" and increases the risk of cesarean section. The technique of repeat cesarean is same as standard lower segment operation except peritoneum should be opened as high as possible and carefully because the bladder may displace upwards and the intestine may be adherent to original wound. Bladder should be reflected with great care because it may be adherent, thus can damage. ${ }^{4}$ This study is carried out at a district hospital in a small city of Dumka in Jharkhand, to analyze the demographic variables, indications of cesarean and feto-maternal outcome in cases of post cesarean pregnancy.

\section{METHODS}

This was a retrospective observational study, carried out in Sadar hospital Dumka, in department of obstetrics and gynecology in 1 year duration from July 2020 to June 2021. Data obtained from labor room and medical record department. Out of 261 total cesarean held during this period, 63 were post cesarean patients. Case sheets of previous cesarean patients were analyzed irrespective of their parity, to determine their incidence, indications, demographic variables and feto-maternal outcome. Referred out patients were excluded from the study. The cases that came in active labor with adequate pelvis and average size baby and no signs of scar tenderness and fetal distress were given trial of labor and monitored properly.

\section{RESULTS}

Out of 2947 deliveries during this period, 95 patients were admitted with previous cesarean. 32 were referred to higher centre due to associated morbidities like rupture uterus, severe anaemia, pulmonary edema, unconscioussness in eclampsia, jaundice etc. as they may need general anaesthesia and ICU facilities, thus the prevalence of previous CS patients here is $3.22 \%$. Out of 95, 63 were managed and deliver here, so the incidence of previous CS managed here was $2.13 \%$. 25 (39.7\%) deliver by VBAC and $38(60.3 \%)$ by cesarean section. As depicted in (Table 1), maximum 95.2\% cases were between 21-30yrs of age group. All VBAC were among this age group only. 3 cases $(4.8 \%)$ were elder than 30 yrs and all went for LSCS.

Table 1: Demographic variables.

\begin{tabular}{|c|c|c|c|c|c|}
\hline Variables & & $\begin{array}{l}\text { Frequency } \\
(\mathrm{N}=63)\end{array}$ & $\%$ & $\begin{array}{l}\text { Frequency }(\%) \text { VBAC } \\
(\mathbf{N}=25)\end{array}$ & $\begin{array}{l}\text { Frequency (\%) CS } \\
(\mathrm{N}=38)\end{array}$ \\
\hline \multirow{3}{*}{ Age (years) } & $<20$ & 0 & - & - & - \\
\hline & $21-30$ & 60 & 95.2 & $25(100)$ & $35(92.1)$ \\
\hline & $>30$ & 3 & 4.8 & - & $3(7.9)$ \\
\hline \multirow{2}{*}{ Status } & Tribal & 16 & 25.4 & $12(48)$ & $4(10.5)$ \\
\hline & Non-tribal & 47 & 74.6 & $13(52)$ & $34(89.5)$ \\
\hline \multirow{2}{*}{ Registration } & $\begin{array}{l}\text { Booked ( } 3 \text { or more } \\
\text { ANC) }\end{array}$ & 15 & 23.8 & $4(16)$ & $11(28.9)$ \\
\hline & Unbooked (<3 ANC) & 48 & 76.2 & $21(84)$ & $27(71.1)$ \\
\hline \multirow{3}{*}{ Parity } & G2 & 50 & 79.4 & $15(60)$ & $35(92.1)$ \\
\hline & G3 & 7 & 11.1 & $5(20)$ & $2(5.3)$ \\
\hline & G4 or more & 6 & 9.5 & $5(20)$ & $1(2.6)$ \\
\hline \multirow{2}{*}{$\begin{array}{l}\text { Gestational age } \\
\text { (weeks) }\end{array}$} & $<3$ & 4 & 6.3 & - & $4(10.5)$ \\
\hline & $>37$ & 59 & 93.7 & $25(100)$ & $34(89.5)$ \\
\hline \multirow{3}{*}{ Birth space } & $<18$ months & 4 & 6.3 & $1(4)$ & $3(7.9)$ \\
\hline & 18 months- 3 years & 14 & 22.2 & $5(20)$ & $9(23.6)$ \\
\hline & >3years & 45 & 71.5 & $19(76)$ & $26(68.4)$ \\
\hline
\end{tabular}


Approx one-fourth (16 cases) were from tribal population and 12 deliver vaginally among them. Three-fourth patients were unbooked due to lack of knowledge and resources as mostly came from remote areas. $50(79.4 \%)$ patients had conceived $2^{\text {nd }}$ time and $6(9.5 \%)$ patients were gravida 4 or more with previous abortion, vaginal delivery followed by cesarean or cesarean followed by $2^{\text {nd }}$ or $3^{\text {rd }}$ VBAC. $93.7 \%$ cases were term. 4 cases had birth interval $<18$ months so 3 went for CS and 1 came in $2^{\text {nd }}$ stage of labor deliver vaginally. Maximum 19 VBAC patients had birth interval of $>3$ years.

Table 2: Indications of cesarean in previous cesarean section.

\begin{tabular}{|lll|}
\hline Indications & $\begin{array}{l}\text { Frequency } \\
(\mathbf{N}=63)\end{array}$ & $\%$ \\
\hline $\begin{array}{l}\text { Prom with } \\
\text { oligohydramnios }\end{array}$ & 22 & 34.9 \\
\hline Fetal distress & 17 & 27 \\
\hline $\begin{array}{l}\text { Cephalopelvic } \\
\text { disproportion }\end{array}$ & 16 & 25.4 \\
\hline Malpresentation & 7 & 11.1 \\
\hline On maternal request & 1 & 1.6 \\
\hline
\end{tabular}

Indications made by obstetrician in previous cesarean section are shown in (Table 2). The most common indication found as per patient and their discharge papers were PROM, followed by fetal distress and cephalopelvic disproportion, i.e., $34.9 \%, 27 \%, \quad 25.4 \%$ respectively. There was only one case done on maternal request in a highly educated woman. Out of $63, \mathrm{CS}$ of 41 patients was done in private nursing home.

Table 3: Indications of repeat cesarean section.

\begin{tabular}{|lll|}
\hline Indications & $\begin{array}{l}\text { Frequency } \\
(\mathbf{N}=38)\end{array}$ & $\%$ \\
\hline Scar tenderness & 15 & 39.5 \\
\hline Fetal distress & 2 & 5.3 \\
\hline Malpresentation & 2 & 5.3 \\
\hline $\begin{array}{l}\text { Cephalopelvic } \\
\text { disproportion }\end{array}$ & 6 & 15.8 \\
\hline Oligohydramnios & 3 & 7.9 \\
\hline PIH & 3 & 7.9 \\
\hline On maternal request & 3 & 7.9 \\
\hline Big size baby (>3.5kg) & 2 & 5.3 \\
\hline Bad obstetric history & 2 & 5.3 \\
\hline
\end{tabular}

As depicted in (Figure 1), TOLAC was given in 25 cases and all deliver vaginally without ventuse or forceps assistance. All were came in active labour or in $2^{\text {nd }}$ stage of labor with having. 19 cases were had previous child birth 3yrs back or more, 5 between 18 months to $3 y$ rs and only one came in $2^{\text {nd }}$ stage of labor with previous child birth 16 months back. Out of 38 cesarean cases, 30 $(78.9 \%)$ went for emergency cesarean and $8(21.1 \%)$ went for elective cesarean section. The most common indication found here was previous cesarean with scar tenderness $(39.5 \%), 2^{\text {nd }}$ being CPD (15.8\%) followed by, oligohydramnios, PIH and on maternal request, each $7.9 \%$. Incidence of each indication is shown in (Table 3). $19(13.2 \%)$ out of 63 opted for PPIUCD application and bilateral tubal ligation was done in $18(28.5 \%)$ cases. 1 more case opted for ligation, but couldn't be done due to dense adhesions between anterior abdominal wall and anterior surface of uterus, thus has been counseled for vasectomy to her partner.

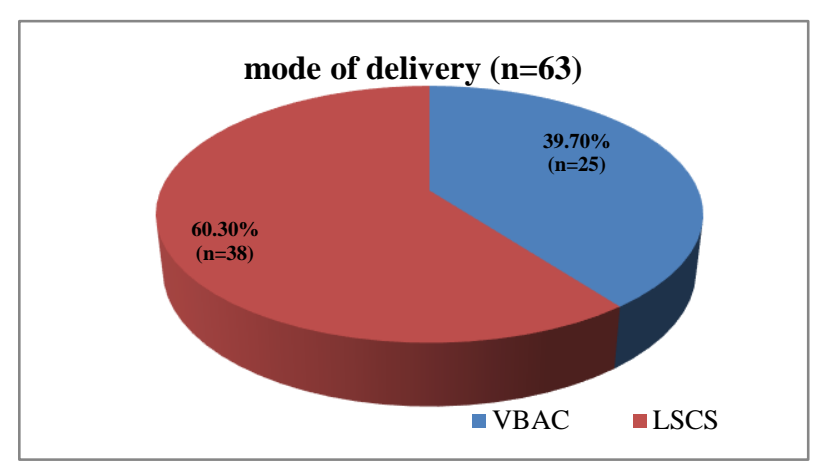

Figure 1: Mode of delivery (VBAC and LSCS).

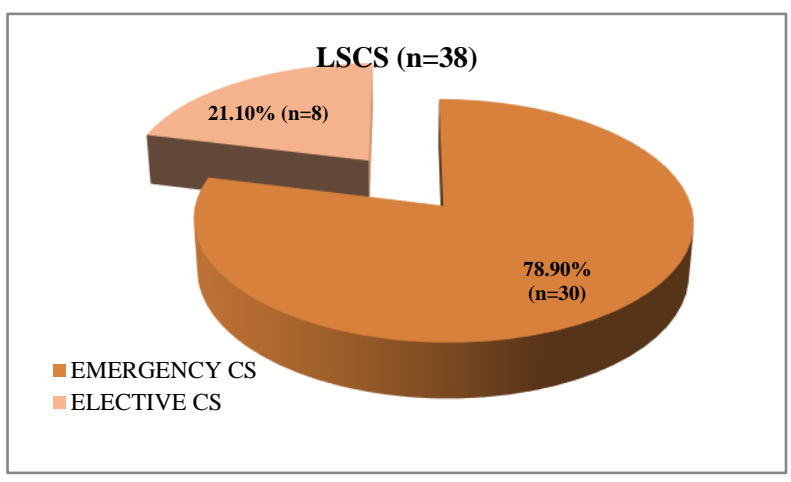

Figure 2: Distribution of LSCS mode of delivery.

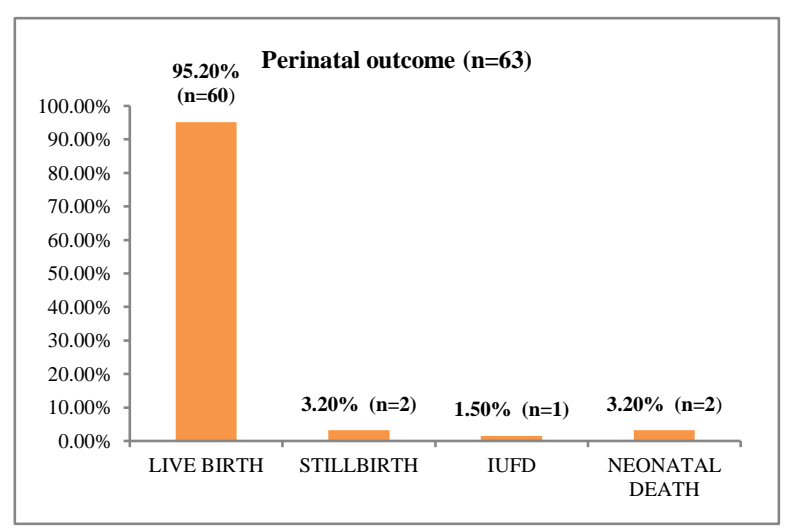

Figure 3: Perinatal outcome.

Rest $26(41.3 \%)$ opted for other methods of contraception. As shown in (Table 4), cosmetically bad hypertrophic skin scar was observed in $19 \%$ of cases, in which mostly had history of wound infection in previous cs. PPH occurred in $3(4.8 \%)$ cases, 2 had atonic and 1 had traumatic PPH. Blood transfusion required in these 3 
cases and 13 more cases (total 25.4\%) required blood or

injectable iron sucrose due to anemia.

Table 4: Maternal morbidities.

\begin{tabular}{|c|c|c|c|c|}
\hline Morbidities & $\begin{array}{l}\text { Frequency } \\
(\mathrm{N}=63)\end{array}$ & $\%$ & $\begin{array}{l}\text { Frequency (\%) } \\
\text { VBAC }(\mathbf{N}=\mathbf{2 5})\end{array}$ & $\begin{array}{l}\text { Frequency (\%) } \\
\text { CS }(\mathrm{N}=38)\end{array}$ \\
\hline Hypertrophic skin scar & 12 & 19 & $7(28)$ & $5(13.2)$ \\
\hline PPH & 3 & 4.8 & $1(4)$ & $2(5.3)$ \\
\hline Blood transfusion and injectable iron & 16 & 25.4 & $10(40)$ & $6(15.8)$ \\
\hline Prolong Foley's catheterization $>72 \mathrm{hrs}$ & 14 & 22.2 & $1(4)$ & $13(34.2)$ \\
\hline Wound infection and gape & 3 & 4.7 & - & $3(7.9)$ \\
\hline $\begin{array}{l}\text { Prolong hospital stay (>8 days in CS and } \\
>72 \text { hrs in VBAC cases) }\end{array}$ & 5 & 7.9 & $1(4)$ & $4(10.5)$ \\
\hline
\end{tabular}

Table 5: Intraoperative findings.

\begin{tabular}{|lll|}
\hline Findings & $\begin{array}{l}\text { Frequency } \\
\text { N=38 }\end{array}$ & $\%$ \\
\hline Dense adhesions & 6 & 15.8 \\
\hline $\begin{array}{l}\text { Scar dehiscence and scar } \\
\text { rupture }\end{array}$ & 7 & 18.4 \\
\hline Adherent bladder & 7 & 18.4 \\
\hline Uterine artery ligation & 1 & 2.6 \\
\hline Adherent placenta & 1 (focal) & 2.6 \\
\hline
\end{tabular}

Table 6: Fetal outcome in VBAC and CS.

\begin{tabular}{|c|c|c|c|c|}
\hline Outcome & $\begin{array}{l}\text { Frequency } \\
\text { VBAC } \\
(\mathrm{N}=\mathbf{2 5})\end{array}$ & $\%$ & $\begin{array}{l}\text { Frequency } \\
\text { CS }(N=38)\end{array}$ & $\%$ \\
\hline Live birth & 23 & 92 & 37 & 97.4 \\
\hline stillbirth & 2 & 8 & - & - \\
\hline IUFD & - & - & 1 & 2.6 \\
\hline $\begin{array}{l}\text { Transient } \\
\text { tachypnea } \\
\text { of newborn }\end{array}$ & 1 & 4 & 4 & 10.5 \\
\hline $\begin{array}{l}\text { Birth } \\
\text { asphyxia }\end{array}$ & 2 & 8 & 1 & 2.6 \\
\hline $\begin{array}{l}\text { Neonatal } \\
\text { death }\end{array}$ & 1 & 4 & 1 & 2.6 \\
\hline
\end{tabular}

Wound infection occurred in $3(4.7 \%)$ emergency CS cases but none of them had wound gape. Foley's catheterization for $>72$ hours required in 14 (22.2\%) cases, out of which 1 in VBAC and rest in cesarean cases. Average hospital stay was $48 \mathrm{hrs}$ in VBAC and 7-8 days in CS patients. Prolong hospital stay, i.e. $>72$ hours in VBAC and $>8$ days in CS patients were observed in 5 (7.9\%) cases including 1 VBAC stayed prolong due to urgency and difficulty in micturition. As depicted in (Figure 3 and Table 6), the incidence of babies born alive were $60(95.2 \%) .2(3.2 \%)$ were stillborn in VBAC cases and $1(1.5 \%)$ was IUD big size baby in CS case. Transient tachypnea in newborn observed in $4(10.5 \%)$ of CS cases and in $1(4 \%)$ case of VBAC. $2(8 \%)$ asphyxiated babies born vaginally and 1 (2.6\%) in CS case. Total 8 babies were admitted in NICU as per record, due to birth asphyxia and neonatal jaundice, out of which
2 (1 had vaginal delivery and 1 delivered by CS) died within 28 days of birth.

\section{DISCUSSION}

In National Family Health Survey 2015-16, the rate of cesarean section in India was $17.2 \%$. in 1985, WHO stated, "There is no justification for any region to have CS rates higher than $10-15 \% .{ }^{12}$ But this cannot be taken as hallmark as it was limited by either having incomplete data or relying on averaged CS delivery rates from multiple years without accounting for year to year variation in these estimates. ${ }^{13}$ Here, the overall CS delivery rate was $8.8 \%(261 / 2947)$, incidence of managed cases in previous cesarean section was $2.13 \%$ and the prevalence of previous cesarean patients was $3.2 \%$. This is very less than the rate observed in a prospective study at Nigeria. ${ }^{5}$

An obstetrician always faces a challenge in deciding the mode of delivery in previous cesarean cases. Selection of candidates for VBAC according to ACOG 2004 guidelines are, should have no more than one prior LSCS, should have adequate pelvis, no previous history of classical CS or rupture, average size baby, a well equipped centre and preferable in patients come in spontaneous labor. As it is a district hospital at a small city of Jharkhand, so previous cesarean patients with associated severe complications were referred to higher center and 63 prior CS cases were managed and delivered. $25(39.7 \%)$ deliver vaginally and $38(60.3 \%)$ by repeat cesarean section. $8(12.7 \%)$ went for elective CS and $30(47.6 \%)$ for emergency CS. This is almost similar to the rates shown in Iyer et al study and near to the values given by Rahman et al in Dhaka., ${ }^{7,9}$ The rate of VBAC was less in a study done at grant medical college, Mumbai by Poornima and very high in Joshi et al study. ${ }^{1,2}$ TOLAC was only given in patients who came in active labor with adequate pelvis, average size baby and no signs of scar dehiscence or fetal distress. A prospective observational study in Egunu, Nigeria, which is also a developing country like India showed $24 \%$ VBAC rate, which is less than the rate in present study and they had comparatively higher repeat cesarean section rates. ${ }^{5}$ 
In present study, maximum $(95.2 \%)$ patients were between 21-30yrs, comparable to other studies. ${ }^{1,9,11}$ All VBAC were among this age group only. $76.2 \%$ patients were unbooked and only $23.8 \%$ were booked, opposite to Poornima and Nazma et al studies., ${ }^{1,6}$ Most of the unbooked were from remote areas and came in active labor, thus maximum deliver vaginally. $1 / 4^{\text {th }}$ of the cases were from tribal population and $3 / 4^{\text {th }}$ were non-tribal. As it is an area having high density of tribal population yet, the rate of $\mathrm{CS}$ is more among non-tribal population, may be due to better living status, education, easy availability of obstetric care to them than in tribal areas. This can be compare to the study done by Desai et al in 2017 in Gujarat. ${ }^{7,10} 79.4 \%$ patients in present study were gravida 2 and $9.5 \%$ were gravida 4 or more with previous abortion 1 or 2 VBAC. In other studies too, maximum were gravid $2 .{ }^{1,6} 93.7 \%$ cases were term, which is near to the rate shown in same studies. ${ }^{1,6} 93.7 \%$ patients had birth space of $>18$ months. So, out of 25,24 VBAC patients were among them. Only 1 patient with $<18$ months of history of prior CS deliver vaginally as she came in $2^{\text {nd }}$ stage of labor.

The indications of prior CS in most of the cases were PROM with oligohydramnios, and were mostly done in private nursing home and among them, most were from non-tribal population. This may be due to the fear of neonatal morbidity, mortality, over-practice of CS in private set up and may be the fear of litigation among the obstetrician due to feto-maternal morbidity. Among 38 cases, $30(78.9 \%)$ went for emergency CS and 25 $(21.1 \%)$ for elective CS. The most common indication being scar tenderness (39.5\%) followed by CPD (15.8\%), very much similar to the rates shown by Poornima et al, Rahman et al and Devakare et al studies., ${ }^{1,11}$ Other studies showed fetal distress as the most common cause followed by scar tenderness. ${ }^{6,2,8}$ The indications for planned CS were, on maternal request (7.9\%), big size baby and $\mathrm{BOH}$, each being $5.3 \%$. Same reasons shown by Poornima in her study. ${ }^{1}$

Coming to maternal morbidity, $12(19 \%)$ previous CS patients had hypertrophic skin scar with few having history of wound infection. Intraoperatively, severe adhesions between anterior abdominal wall, uterus and with omentum were found in $6(15.8 \%)$ cases which is almost near to observation of Iyer. ${ }^{5,7}$ Its higher rate shown in Nazma study and half in Mengesha et al study. ${ }^{6,14}$ Bladder adherence was found in $18.4 \%$ cases but managed appropriately and dissected down by sharp dissection to prevent bladder injury. Scar dehiscence and scar rupture was found in $18.4 \%$ cases, all in emergency CS cases, which is higher than shown in other studies. $7,9,6,14$ But in these studies these patients were given TOLAC. Out of 7, 3 cases had prior CS $<18$ months and 4 between 18 months-3 years, showing that interconceptional duration is an important determinant for condition of scar. Uterine artery ligation required in only $1(2.6 \%)$ case, due to extension of uterine incision. PPH occurred in $3(4.8 \%)$ cases only. 2 was atonic, 1 in each,
VBAC and CS case, and 1 was traumatic, where incision was extended. This is comparable to Rahman et al study and more than observed in Nazma et al study. ${ }^{9,6}$ Its risk is less in planned cases. Blood transfusion and injectable iron was given in $16(25.4 \%)$ cases due to PPH (3) and anemia (13). Approx $25 \%$ among them were tribal people. Infection of the wound is one of the most common complication of cesarean delivery. Here the rate of wound infection found was $4.7 \%$ and all were among emergency cesarean cases, but no one required secondary suturing. There is more risk of wound infection in unplanned surgeries. All 3 were obese. This is nearly equal as observed by Megnesha et al. ${ }^{14}$ The rate was double of this in K P Nazma et al and half in Rahman R. et al study. 6 ,9 $\mathrm{Hb}$ status, intactness of membrane, nutritional and hygienic status of the patient and duration of hospital stay are some determinant of the wound infection. Focal adherent placenta found in 1 (2.6\%) emergency CS case, which was removed and bleeding bed was sewed with multiple sutures and hemostasis done. As shown in (Table 4), prolong hospital stay was in $7.9 \%$ cases, probably due to wound infection, late suture removal in anemic patient, prolong Foley's catheterization. This is comparatively more among CS cases so increases the financial burden on family and burden on health system and strain on overcrowded obstetrics units in district hospital like ours. This result is comparable to Devkare et al study, very less than the Poornima study and nearly equal to Megnesha et al study. ${ }^{1,11,14}$ Foley's catheterization $>72$ hours required in $14(22.2 \%)$ cases. 1 VBAC case required $>72$ hours catheterization due to difficulty in micturition and rest in $13 \mathrm{CS}$ in adherent bladder, scar dehiscence and scar rupture cases, showing high incidence of prolong catheterization in $\mathrm{CS}$ cases in comparison to VBAC cases. There was no case of uterine rupture or maternal death.

This study favors towards the more morbidity among previous cesarean cases and repeat cesarean section is more risky in them. TOLAC should always be tried in cases which fulfills the criteria for VBAC. In terms of perinatal outcome, 60 babies born alive, i.e., 95.2\%. 2 $(3.2 \%)$ were stillborn, both delivered vaginally and 1 was IUD, delivered by CS due to CPD. TTN was more seen in cases went for emergency CS. The incidence of birth asphyxia was more found in babies delivered by VBAC than CS. $2(3.2 \%)$ neonatal death, 1 in each, VBAC and CS case.

\section{CONCLUSION}

The most important dilemma faced by obstetrician in cases of previous cesarean section is either to give TOLAC or to go for repeat CS. When there is some associated complication like PIH, fetal distress, one should go for CS but in uncomplicated cases TOLAC should be tried, to reduce the maternal and neonatal morbidity. An obstetrician and staff should be vigilant in TOLAC and should only be tried in a well equipped 
center to reduce the risk of scar dehiscence and birth asphyxia due to fetal distress. These patients should be frequently observed in ANC clinic, to assess whether they can go for TOLAC or repeat CS may require, and if criteria of TOLAC are not being fulfilled, they should be plan for elective cesarean section. It is also important to analyze the equitable distribution of emergency obstetric care among tribal population as they are mostly at risk, and are mostly being referred from remote areas or come after trial by Dais. This is because of lack of availability of emergency obstetric care, knowledge and financial constraints among them. The maternal age, education, parity, numbers of ANC, birth space, gestational age, socio-economic status are some of the important determinants of cesarean section rates. Many a times, due to limited facilities of fetal monitoring at different hospitals, obstetrician tend towards cesarean section but the trend of CS on demand and its malpractice in primigravida should be curbed to reduce the morbidity associated with multiple CS. Hence, there is need of accreditation of system for regulation of private hospitals to ensure rational practice of CS. This will help to reduce the incidence of primary $\mathrm{CS}$, thus will reduce the rate of repeat $\mathrm{CS}$ and pose less risk and morbidity to the mother and fetus both and will improve the outcome.

\section{ACKNOWLEDGEMENTS}

Authors would like to thank labor room and medical record department staff who helped in completion of this study. Authors would also like to thank all patients who participated in present study.

Funding: No funding sources Conflict of interest: None declared

Ethical approval: The study was approved by the Institutional Ethics Committee

\section{REFERENCES}

1. Poornima M. Pregnancy complicated by previous cesarean section: a retrospective study. Int J Reprod Contracept Obstet Gynecol. 2018;7(11):4470-5.

2. Joshi S, Parmar M. A study of outcome of pregnancy in patients with previous cesarean section in a tertiary care set up. Indian J Obstet Gynecol Res. 2017;4(3):288-91.

3. Cunningham L, Bloom D, Hoffman CS. Prior cesarean delivery. In: Williams obstetrics. 25th ed.
United States of America: Mcgraw Hill; 2009:591600 .

4. Misra R, Gupta N. Repeat cesarean section. In: Donald's Practical obstetric problems. 7th ed. India: Wolters Kluwer; 2014:584-6.

5. Ugwu GO. Maternal and perinatal outcomes in delivery after a previous cesarean section in Enugu, South-east Nigeria: a prospective observational study. Int J Women's Health. 2014;6:301-5.

6. Nazma KP, Rao SB. Pregnancy outcome in women with previous one cesarean section. Int J Sci Res. 2015;4(1):375-7.

7. Iyer SM, Hariani VA. Maternal and fetal outcomes in previous one cesarean pregnancies. J Med Sci Clin Res. 2016;4(1):8800-3.

8. Singh AK. Study of frequency and indications of cesarean section in a tertiary care hospital of Garhwal-Uttarakhand, India. J Res Med Edu Ethics. 2011;1(2):122-4.

9. Rahman R. The outcome of vaginal birth after cesarean section (VBAC): Descriptive Study. Med Today. 2013;25(1):14-7.

10. Desai G, Anand A. Rates, indications and outcomes of Cesarean section deliveries: A comparison of tribal and non-tribal women in Gujarat, India. PLoS ONE. 2017;12(12):e0189260.

11. Devkare V. Maternal and fetal outcome of VBAC after first previous LSCS in a Tertiary care teaching hospital of western India. Int J Curr Res Med Sci. 2017;3(7):8-17.

12. World health organization. Appropriate technology for birth. Lancet. 1985;2:436-7.

13. Molina G, Weiser TG, Lipsitz SR. Relationship between cesarean delivery rates and maternal \& neonatal mortality. JAMA. 2015;314:2263-70.

14. Mengesha MB. Maternal and fetal outcomes in cesarean delivery and factors associated with its unfavorable management outcomes; in Ayder specialized comprehensive hospital, Mekelle, Tigray. BMC Res Notes. 2019;12:650.

Cite this article as: Sharma T, Singh S. Fetomaternal outcome in previous one cesarean section: a retrospective observational study at a district hospital of Jharkhand. Int J Reprod Contracept Obstet Gynecol 2021;10:3834-9. 